\title{
O USO DO FACEBOOK PARA O TRABALHO COM AS RELAÇȮES DE GÊNEROS E
}

\author{
SEXUALIDADES: POTENCIALIDADES PARA A AMPUIAÇÃO \\ DOS MULTILETRAMENTOS NA FORMAÇÃO DOCENTE ${ }^{1}$
}

Jaciluz Dias ${ }^{2}$

\begin{abstract}
Resumo: Em meio a tantos (com)textos próprios da era digital, o Facebook pode ser concebido como uma ferramenta para a efetivação de várias práticas educativas. Este artigo tem como objetivo analisar essa questão, a partir de dados coletados em um curso realizado por meio do Facebook. A formação docente, inicial ou continuada, ainda é carente nas discussões que envolvem gêneros e sexualidades (SILVA, 2015). Ainda mais quando é feita uma problematização a partir da ótica pós-estruturalista (LOURO, 2012), associada à habilidade de multiletramentos (ROJO, 2015). O Facebook pode, então, ser considerado uma ferramenta potencializadora de conhecimentos, constituindo-se como um material didático que conjuga o aperfeiçoamento de habilidades conceituais e de análises metodológicas à ampliação de saberes relacionados aos multiletramentos.
\end{abstract}

Palavras-chave: Formação docente. Relações de gêneros e Sexualidades. Artefatos multimídias. Intermultimidialidade. Tecnologias digitais.

Introdução

Esta pesquisa é uma tentativa de apontar caminhos para potenciais usos dos artefatos multimídias na melhoria da qualidade dos processos educativos, mais especificamente, nas discussões sobre relações de gêneros e sexualidades. Para tanto, busquei investigar como utilizar artefatos multimídias para ampliar as oportunidades de formação de educadoras e educadores ${ }^{3}$ sobre as temáticas relações de gêneros e sexualidades? E, a partir disso, que saberes/ representações sobre essas temáticas podem ser observados em produções realizadas por participantes de um curso de extensão sobre esse tema?

Faz-se importante, neste ponto, uma pausa para discorrer sobre o motivo da minha escolha pela pluralização da palavra gênero, mesmo sendo mais comum, nas pesquisas nessa área, a

\footnotetext{
${ }^{1}$ Este artigo constitui-se um recorte da minha trabalho de mestrado, intitulada Tessituras multimidiáticas: linguagens, tecnologias e sexualidades, a qual pode ser acessada no site www.ded.ufla.br/tessituras.

${ }^{2}$ Mestra em Educação, Universidade Federal de Lavras - UFLA, jaciluz.fonseca@prgdp.

ufla.br.

3Entendendo a língua como instrumento de difusão de conhecimento e, portanto, ferramenta de exercício de poder, vejo o uso comum - e exigido pela gramática normativa - de generalizações no gênero masculino como algo contraditório ao que pretendo com esta pesquisa. Portanto, como busco problematizar questões ligadas às relações de gêneros e sexualidades, atentei-me em utilizar ambos os gêneros quando há referências a pessoas.
} 
utilização da expressão relações de gênero, por entender-se que o sentido da pluralidade está na palavra relações. Contudo, decidi utilizar relações de gêneros por entender que, além de as relações serem plurais, diversas também são as identidades de gênero. Sustento, então, a minha escolha em concepções como a de Joan Wallach $\operatorname{Scott}^{4}(1995$, p. 75), que entende o gênero como "categoria social imposta sobre um corpo sexuado". Logo, esse conceito está relacionado a identidades, as quais podem ser múltiplas, do que decorre que vários podem ser os gêneros.

Embaso a minha decisão, ainda, em Judith Butler (2003, p. 199), que defende a noção de gênero relacionada à de atitude "os gêneros distintos são parte do que "humaniza" os indivíduos na cultura contemporânea [...]. Os vários atos de gênero criam a ideia de gênero, e sem esses atos, não haveria gênero algum". Concordo, portanto, com essa ótica, na medida em que a filósofa contemporânea questiona o que se entende por gênero como algo cristalizado e estático, binário e polarizado, a partir da construção social de que o ser humano só pode ser visto ou como homem ou como mulher, quando, na verdade, seu gênero expressará particularidades que são próprias de cada pessoa.

E já que trato de conceitos da linguagem, sopeso importante estabelecer um diálogo entre áreas do conhecimento, nesse caso, entre os estudos sobre gêneros e sexualidades e a linguística, já que gênero é um termo originalmente utilizado para classificar gramaticalmente as palavras (STELLMANN, 2007) e utilizado também para designar gêneros textuais, cuja premissa básica é a multiplicidade, segundo Luiz Antônio Marcuschi (2008).

Ainda no que se refere a esse assunto, é necessário pontuar que os estudos filosóficos já estão sendo incorporados às pesquisas na área da educação, em que alguns/mas pesquisadores/as também já utilizam gênero no plural. Para Guacira Lopes Louro (2012), "a concepção dos gêneros como se produzindo dentro de uma lógica dicotômica implica um polo que se contrapõe a outro (portanto uma ideia singular de masculinidade e de feminilidade), e isso supõe ignorar ou negar todos os sujeitos sociais que não se "enquadram" em uma dessas formas" (p. 34, grifo da autora). Mais que vistas como polos opostos, as pessoas precisam ser entendidas como parte de um todo, o qual é dinâmico e diverso.

Vários podem ser os temas-foco da análise intermultimídia, mas escolhi relações de gêneros e sexualidades por acreditar que a reflexão sobre essa temática é necessária, mas ainda é pouco discutida na escola. Isso acontece não somente por ser esse um assunto considerado polêmico, mas,

4 Destaco a escolha pela identificação das autoras e dos autores por meio de nome e sobrenome. Sei que as normatizações da Associação Brasileira de Normas Técnicas (ABNT) recomendam o uso apenas do sobrenome. Contudo, entendo que isso descaracteriza o protagonismo da mulher enquanto pesquisadora, já que a associação automática feita a um sobrenome é ao gênero masculino. $E$, se pretendo, como já dito, problematizar questões ligadas às relações de gêneros e sexualidades, a citação às pesquisadoras e aos pesquisadores referidas/os precisa estar em consonância com esse posicionamento. 
também, pela falta de ferramentas que possibilitem o trabalho com o tema. Daí adveio a ideia de um curso de extensão, para 70 licenciandas/os da Universidade Federal de Lavras (UFLA), com as temáticas das relações de gêneros e sexualidades. Intitulado Corpo, saúde, sexualidades, o curso teve duração de 40 horas e formato híbrido ${ }^{5}$, já que se dividiu em dois encontros presenciais, que totalizaram 10 horas, mas aconteceu, primordialmente, a distância, durante 30 horas, tendo como ferramenta didática a rede social Facebook.

Entendo que a relevância desta investigação científica advém, primeiramente, de ser ela uma possibilidade de discutir sobre as temáticas relações de gêneros e sexualidades. Essa discussão, apesar de necessária no âmbito da educação e recorrente em situações da escola, ainda aparece quando aparece - de modo tímido nos cursos de formação docente, segundo Kelly da Silva (2015). Essa realidade, inclusive, foi comprovada por meio da análise das matrizes curriculares dos cursos de licenciatura da UFLA, nos quais é rara a presença de disciplinas voltadas para o estudo das relações de gêneros e sexualidades.

Não inserir essas temáticas na formação inicial docente acaba por reverberar consequências nas práticas pedagógicas das/os futuros professores, dificultando a abordagem do tema na escola. Quiçá quando esse tema não é censurado, haja vista a polêmica, ocorrida em 2014, sobre incluir ou retirar os termos gênero e sexualidades dos planos nacional, estaduais e municipais de educação.

É necessário lançar luz a uma temática cuja discussão apresenta constantes avanços e recuos e que, por isso, é marcada por contradições, mas que vem ganhando cada vez mais espaço público discursivo. Ressalta-se, nesse contexto, que não basta que a temática apenas conste em currículos, seja da educação básica seja do ensino superior. É importante que diferentes disciplinas tratem sobre relações de gêneros e sexualidades e discutam aspectos da realidade dos/as alunos/as, promovendo uma formação crítica e mais cidadã (SILVA, 2015).

Justifica-se a pertinência da pesquisa por ela tratar do uso das TDIC, tão corriqueiras no cotidiano, mas ainda subutilizadas no processo educacional (MORAN, 2011). Exemplos disso são as redes sociais que, com as múltiplas ferramentas de interação que oferecem, são um recurso que já deveria ser mais explorado na escola, tendo em vista ser parte da realidade atual. Entre essas ferramentas de interação, escolheu-se para o curso o Facebook, devido as suas potencialidades aplicáveis ao processo de ensino-aprendizagem.

Neste trabalho reuniram-se referenciais teóricos ligados às sexualidades, à linguística e às tecnologias, buscando demonstrar como a interseção entre elas pode contribuir para a educação. E, ainda, como as teorizações e análises propostas pretendem lançar novos olhares para a forma como

5 A educação a distância (EAD) que mescla ensino presencial e virtual é denominada mista, blended ou híbrida. Por entender que este último termo traduz satisfatoriamente o termo em inglês e contempla os objetivos desse tipo de ensino, escolhi utilizá-lo ao longo deste trabalho. 
se pensam os processos educativos. Por isso, esta investigação poderá servir de fonte de consulta para futuras pesquisas.

\section{Pressupostos teóricos}

As três áreas envolvidas nesta pesquisa permitem fazer uso de diferentes analogias conceituais, mas que comungam do mesmo sentido. Inicialmente, o rizoma, conforme proposto por Gilles Deleuze e Félix Guattari (1995), conceito que advém da botânica, para um tipo de raiz, e é transposto para as ciências humanas, carregando o sentido de multiplicidade, algo sem início e fim determinados, mas entre partes, viabilizando conexões.

Esse conceito, transposto para o mundo virtual das TDIC, é conhecido como rede ${ }^{6}$, que nomeia um "sistema interligado de computadores, para comunicação e troca de dados" e, ainda, é sinônimo para internet, tamanho os caminhos e conexões que ela permite. Mas rede é, antes, em seu sentido original, um "entrelaçamento de fios, cordões, arames etc., formando uma espécie de tecido de malha com espaçamentos regulares, em quadrados ou losangos, relativamente apertados, que se destina a diferentes usos". É, portanto, um tipo de tecido.

$E$, sabendo que tecido e texto têm etimologia comum ${ }^{7}$, chega-se à terceira analogia, no campo linguístico. Da mesma forma que fios compõem tecidos, palavras formam textos; além disso, um texto pressupõe o diálogo com outros (DIAS; ALMEIDA, 2016), já que a composição escrita advém de leituras de referências anteriores. Essa aproximação entre textos/discursos é chamada intertextualidade/interdiscursividade.

\subsection{Relações de gêneros e sexualidades na formação docente}

Assim como as tramas que compõem um tecido, diluídas estão pela sociedade as relações de poder, que constroem saberes e instituem verdades, conforme indica Michel Foucault (2014), especialmente quando o assunto é sexo ou qualquer temática relacionada a isso. Por conseguinte, pesquisar relações de gêneros e sexualidades torna-se um desafio, sobremaneira se o foco estiver voltado para a formação de alunos e alunas, em qualquer nível escolar.

O recorte desta pesquisa é o ensino superior, mais especificamente a formação inicial docente, nas licenciaturas, a qual se refletirá em todos os âmbitos da educação formal, tendo em

6 Rede. Acepção retirada do dicionário Michaelis online. Disponível em: http:// michaelis.uol.com.br/busca? $\mathrm{r}=0 \& \mathrm{f}=0$ \&t=0\&palavra=rede. Acesso em: 11 mar. 2017

7 Do latim: Tēxtūră, ǣ (de texere): ação de tecer, tecedura. Tēxtŭs, ūs: (de texere): tecido, enlaçamento, encadeamento, contextura; texto, teor, conteúdo. (SARAIVA, 2006) 
vista que o/a professor/a será um/a multiplicador/a das ideias que aqui são discutidas. Com base nos estudos de Kelly da Silva (2015), tentou-se compreender como as sexualidades estão presentes nos currículos dos cursos de formação docente. A autora faz um levantamento sobre como as relações de gêneros e sexualidades aparecem nos currículos dos cursos de pedagogia de três universidades mineiras. Ela chegou à conclusão de que a temática, quando integra as matrizes curriculares, só pontua disciplinas de outra natureza ou, no máximo, é uma disciplina eletiva, oferecida apenas durante alguns períodos (SILVA, 2015).

No caso desta pesquisa, que se utilizou de um curso de extensão voltado para licenciandas e licenciandos da Universidade Federal de Lavras (UFLA), no sul do estado de Minas Gerais, Brasil, pode-se notar semelhanças com a realidade apresentada pela pesquisadora supracitada. São oito licenciaturas oferecidas pela instituição, em cujas matrizes ${ }^{8}$ buscaram-se os termos gênero e sexualidade, levando à constatação de que: no curso de Física, não havia menção ao tema; já, para os cursos de Educação Física, Filosofia, Letras e Química, aparecia como parte de uma disciplina eletiva (Sociologia da Educação). Para os cursos de Ciências Biológicas e Matemática, era oferecida a disciplina eletiva Relações de Gênero no Mundo do Trabalho. E, diferentemente do que foi constatado por Kelly da Silva (2015), na UFLA, o curso de Pedagogia tem a disciplina obrigatória Educação, Gênero e Sexualidades e a eletiva Sexualidades e Infâncias.

Nesse sentido, oferecer um curso de extensão como o Corpo, saúde, sexualidades, voltado para discussões sobre tal temática, é também uma forma de resistência e auxilia tanto o aprofundamento do que já é visto em alguns cursos quanto a suprir as lacunas de outros. Um indício dessa necessidade está relacionado ao perfil dos/as participantes e os seus cursos, já que das pessoas que se inscreveram: 34 eram de Letras, 5 de Pedagogia, 4 de Educação Física, 2 de Matemática e 2 de Química; além de 1 da Agronomia e 2 do Direito. Ou seja, diante da quantidade de discentes da UFLA, pode-se notar que há uma demanda maior pela formação nesse assunto em cursos que habilitam futuros/as professores/as.

Essas/es licenciandas/os estão em processo formativo e, infiro, muitos pretendem se tornar professoras/es e chegarem à escola, onde se depararão com uma realidade que necessita das discussões sobre gêneros e sexualidades. E, sendo a escola um microcosmo social, ela reproduz os paradigmas vigentes na sociedade em relação a várias temáticas, inclusive quanto às representações de gêneros e aos tabus impostos à discussão sobre sexualidades, conforme defende Guacira Lopes Louro (2012): “É indispensável que reconheçamos que a escola não apenas reproduz ou reflete as

8 As matrizes curriculares podem ser consultadas no site do Sistema Integrado de Gestão (SIG) da UFLA. Disponível em: https://sig.ufla.br/modulos/publico/matrizes curriculares/ index.php. Acesso em: 11 mar. 2017. 
concepções de gênero e sexualidade que circulam na sociedade, mas que ela própria as produz" ( $p$. 80-81).

Assim, considero que as relações de gêneros e sexualidades tornam-se, então, temas que precisam fazer parte do currículo escolar, como tema transversal, que perpasse todas as disciplinas. Todavia, o trabalho com essa temática, ao ser levado para a escola, precisa estar respaldado em diferentes referenciais teóricos. Procuro, então, com esta pesquisa, estabelecer um diálogo entre três áreas: sexualidades, linguística e tecnologias, de tal modo que a última forneça instrumentos que possibilitem o trabalho com a linguagem e a discussão sobre relações de gêneros e sexualidades.

Para tanto, proponho uma reconfiguração, a partir de uma mudança do seu contexto de uso, cunhando o termo artefatos multimídias, conceito que procura englobar um conjunto de objetos, sejam eles reais ou virtuais, analógicos ou digitais, que reúnem texto, som, imagem, entre outros, tratando de um determinado assunto.

\subsection{Conceituando artefatos multimídias e intermultimidialidade ${ }^{9}$}

A terminologia que utilizo provém do conceito de artefato $^{10}$ que, segundo o dicionário, caracteriza um "aparelho, mecanismo ou engenho construído para finalidade específica", ou ainda, para a antropologia e a arqueologia, um "objeto que sofreu alteração provocada pelo homem, em oposição àquele que é resultado de fenômeno natural". No mesmo viés, multimídia ${ }^{11}$ é uma "produção que, fixada em um meio digital, reúne em um único suporte diferentes modalidades de expressão criativa, como, por exemplo, desenho, som, animação, vídeo, texto, performance etc." Artefato multimídia pode ser, portanto, um vídeo do Youtube, uma postagem do Facebook, uma música, um artigo científico, uma reportagem, entre tantos outros exemplos.

Este conceito advém, ainda, de outras duas perspectivas. A primeira delas está relacionada ao conceito de artefato que, segundo Patricia Vasconcelos Almeida (2006), inclui tanto um objeto material (ferramenta) quanto aspectos relacionados ao discurso veiculado por meio deste (ferramentas externas e internas). Já multimídia é um conceito que, segundo Pierre Lévy (1999), advém de mídia: suporte de informação e comunicação. Logo, multimídia se refere ao que emprega o uso de tais suportes. Sendo assim, a reconfiguração que proponho para artefatos multimídias

$9 \quad$ Entendo aqui o ineditismo dos termos artefato multimídia e intermultimidialidade, quando aplicados à área desta pesquisa. O que se comprova por buscas realizadas por meio do Google Acadêmico (Disponível em:

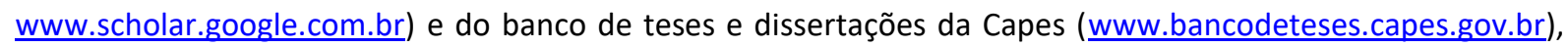
que não retornaram outras pesquisas que utilizam esses termos da forma como utilizei.

10 Artefato. Acepção retirada do dicionário Michaelis online. Disponível em: http:// michaelis.uol.com.br/busca? $r=0 \& f=0 \& t=0 \&$ palavra=artefato. Acesso em: 11 mar. 2017.

11 Multimídia. Acepção retirada do dicionário Michaelis online. Disponível em: http://michaelis.uol.com.br/busca?id=okzE7. Acesso em: 11 mar. 2017 
busca transmitir essa noção dos vários suportes (texto impresso, cinema, internet, entre outros) que veiculam diferentes discursos, seja em linguagem verbal ou não verbal (palavras, imagem, música, gesto etc.).

Os artefatos multimídias utilizados pelo/a o/a professor/a podem tornar mais dinâmica e rica a discussão e mais profícuas as atividades que desenvolve sobre relações de gêneros e sexualidades. Mas, para isso, ele/ela precisa, ainda, desenvolver duas habilidades, tanto para si quanto junto a seus/suas alunos/alunas: saber compreender esses artefatos e seus usos sociais (multiletramentos) e conseguir identificar o diálogo que podem estabelecer entre si, o que acontece de modo simultâneo e contínuo (intermultimidialidade).

Assim, cursos como o Corpo, saúde, sexualidades contribuem para a formação docente e para a aplicação desse conhecimento em sala de aula. Contudo, não adianta dar às/aos futuras/os professoras/es uma receita pronta para que seja apenas aplicada no processo educativo. É importante possibilitar o desenvolvimento da liberdade de escolhas metodológicas, para que ela/ele desenvolva as próprias atividades, de acordo com as turmas em que lecionarão e com aquilo que elas necessitam discutir.

\subsection{Multiletramentos e a "leitura" de mídias}

Para fazer uso adequado dos artefatos multimídias é necessária uma habilidade denominada multiletramentos que, na concepção de Roxane Rojo (2012), é a capacidade e a prática de compreender e produzir textos compostos por muitas linguagens (ou modos, ou semioses) e, portanto, chamados de textos multimodais ou multissemióticos. Esse conceito advém da noção de letramento que, por sua vez, é uma ampliação da alfabetização. Enquanto esta é uma habilidade de decodificação, aquele é a ampliação desse e busca sentido no que há além do simples decodificar. Do mero ato de juntar letras e formar palavras a entender o sentido que elas carregam - ou escondem chega-se hoje à necessidade de saber "ler" imagens, vídeos, sons, o que constitui a habilidade de multiletramentos. Assim, ele acontece quando a decodificação é feita, não apenas no nível do texto, mas das imagens, do som, entre outros.

Mas a noção de multiletramentos é ainda mais que isso, de acordo com a autora supracitada, pois prevê a dimensão cultural da pessoa que tem contato com esses diferentes artefatos multimídias. A compreensão do que se vê, lê, escuta e a relação que se estabelece entre essas ações vai depender do conhecimento de mundo e das habilidades em lidar com esses artefatos. Dessa forma, por exemplo, no caso do Curso Corpo, saúde, sexualidades, a forma como as/os participantes compreenderam os textos, os vídeos, as músicas e as imagens utilizadas nas atividades e os diálogos 
entre esses artefatos - e desses com outros - dependeu do conhecimento prévio que essas pessoas tinham sobre esse material.

Nesse contexto, Roxane Rojo e Jacqueline Barbosa (2015, p. 123) ressaltam as possibilidades de interação que os textos multimodais possibilitam, especialmente no contexto virtual, já que as publicações em redes sociais "podem misturar diferentes linguagens (para além da verbal, vídeos, áudios, imagens de diferentes tipos, estáticas ou em movimento etc.)".

Beth Brait (2013) indica que as atuais práticas de leitura requerem o letramento concomitante em linguagem verbal e em linguagem não verbal: “a dimensão visual interage constitutivamente com o verbal (ou vice-versa), acrescentando-lhe valores. Sem esse jogo não se dá a construção do objeto de conhecimento, nem dos sujeitos da construção e da recepção" (p. 62). É considerando isso que se defende a necessidade de uma formação docente que propicie ao/à futuro/a professor/a saber trabalhar com essas habilidades de leitura, já que a reflexão mobiliza possibilidades de interpretação. E, para conseguir sustentar essas possibilidades de refletir e interpretar, junto com os/as alunos/as, é necessário constituir um referencial teórico que possibilite suscitar direcionamentos de leitura dos textos, de interpretação de imagens e vídeos e das relações entre eles.

A ligação entre o uso social dos multiletramentos, as tecnologias, a linguagem e as opiniões que podem ser expressas por meio dela, inclusive para um posicionamento crítico sobre as temáticas relações de gêneros e sexualidades, advém de um conceito cunhado por David Barton e Carmen Lee (2015) sobre posturas. Segundo esse autor e essa autora, postura "se refere ao posicionamento das pessoas em relação a si mesmas, ao que é dito, e a outras pessoas ou objetos" (BARTON; LEE, 2015, p. 118). E esse conceito é central nas discussões que envolvem as tecnologias e redes sociais, tendo em vista ser esse um espaço muito utilizado para a expressão de opiniões.

\subsection{Intertextualidade/interdiscursividadee odiálogo entre textos/discursos}

A noção de textos que apresentam pontos semelhantes denomina-se intertextualidade que, segundo Ingedore Koch, Anna Christina Bentes e Mônica Cavalcante (2008), é um conceito cunhado por Julia Kristeva, na década de 1960, para a literatura. Assim, o conceito de intertextualidade demonstra que não existe texto que não é intertextual, porque toda escrita, inclusive a acadêmica, utiliza outras fontes, ou seja, não existe um construto textual completamente inédito.

Ingedore Koch, Anna Christina Bentes e Mônica Cavalcante (2008) diferenciam dois tipos de intertextualidade: a lato sensu e a stricto sensu. Enquanto a primeira apresenta-se de modo amplo, no nível do discurso, a segunda é restrita e ocorre entre textos e enunciados. E elas ainda 
subdividem-se em: genérica e tipológica, no caso da lato sensu; e temática, estilística, explícita e implícita, no caso da stricto sensu.

Dessa forma, segundo as autoras, a intertextualidade genérica ocorre quando dois textos guardam semelhanças no modo como se apresentam em relação às características do gênero textual (por exemplo: conto de fadas; carta, entre outros); enquanto a intertextualidade tipológica advém de aproximações quanto às peculiaridades do tipo textual ao qual cada texto pertence (por exemplo: tipo narrativo, argumentativo, entre outros).

Por sua vez, a intertextualidade temática acontece quando dois textos partilham o mesmo tema; já a intertextualidade estilística, quando o estilo de escrita, a forma do texto, assemelha-se. A intertextualidade explícita ocorre quando há uma referência direta a um texto; enquanto a intertextualidade implícita acontece quando quem escreveu o texto conta com o conhecimento de mundo, a bagagem cultural, de quem lê (KOCH; BENTES; CAVALCANTE, 2008).

Assim, o conceito de intertextualidade se amplia para a interdiscursividade, que é o que esta pesquisa propõe a partir da análise de diferentes discursos, em diferentes linguagens: músicas que dialogam com imagens, vídeos que conversam com textos, entre outros. Esses discursos materializam-se em vídeos, imagens, sons, entre outros, o que leva à ampliação da noção de intertextualidade, para o que se denomina, ineditamente nesta pesquisa, intermultimidialidade, que são os diálogos entre os artefatos multimídias.

\subsection{Facebook como ferramenta pedagógica e o ensino híbrido}

A execução do curso foi efetivada por meio da plataforma Facebook, uma rede social que foi criada em 2003 por Mark Zuckerberg, estudante da Universidade de Harvard, com o objetivo de propiciar a comunicação entre os/as estudantes desse centro acadêmico (CORREIA; MOREIRA, 2014). O serviço, que começou com 1.500 participantes, teve sucessivas expansões, até ser acessado, atualmente, por quase dois bilhões de pessoas ${ }^{12}$. A página permite que pessoas que se conhecem possam estabelecer uma rede, compartilhando perfis, experiências, mensagens, imagens, vídeos, entre outros.

Assim, a escolha por esse artefato digital, como plataforma para as atividades virtuais do Curso Corpo, saúde, sexualidades, adveio do fato de essa rede ter por características principais a interação e ser parte da realidade atual. Isso acontece porque, “(...) de forma rápida e dinâmica, toda

12 Em 31 de dezembro de 2016, era 1,86 bilhão. Fonte: Facebook anuncia aumento de lucros e usuários. Disponível em: http://www.em.com.br/app/noticia/internacional /2017/02/01/interna internacional,844286/Facebook-anuncia-aumento-de-lucros-e-usuarios.shtml. Acesso em: 19 mar. 2017. 
e qualquer informação pode ser compartilhada em sites de redes sociais, tornando possível que outros usuários tenham a oportunidade de visualizá-las e de comentá-las" (COUTO JUNIOR, 2012, p. 105).

Além disso, a escolha pelo Facebook também esteve ligada à necessidade de formação dos/as futuros professores, em relação às tecnologias, já que, os processos de ensino-aprendizagem precisam ser ressignificados, o que "inclui a necessidade de uma política de formação de professores que se comprometa a discutir a relação dos jovens com as redes sociais da internet" (COUTO JUNIOR, 2012, p. 136).

Nessa direção, o Curso Corpo, saúde, sexualidades permitiu, não apenas a formação docente no que concerne às relações de gêneros e sexualidades, mas também, por meio da prática com o uso das redes sociais, que os/as futuros professores/as pudessem ter contato com mais uma ferramenta de ensino. $E$, mais ainda, isso feito a partir de um novo modelo de ensino-aprendizagem, o qual está começando a ganhar corpo no Brasil: o ensino híbrido, que, segundo Alexsandro Sunaga e Camila Sanches de Carvalho (2015, p. 144), é "um programa de educação formal no qual o aluno aprende pelo menos em parte por meio do ensino on-line, com algum elemento de controle do estudante sobre o tempo, lugar, modo e/ou ritmo do estudo, e em parte uma localidade física supervisionada, fora de sua residência".

Rodrigo Abrantes da Silva e Ailton Luiz Camargo (2015) apontam que a diferença em relação à educação a distância (EAD) tradicional está no fato de que o foco deixa de ser a transmissão do conhecimento pelo/a professor/a e o/a aluno/a estuda em diferentes situações, ficando a sala de aula apenas como espaço para tirar dúvidas em relação ao que já foi estudado e discutido com colegas e professores/as antes.

Esses autores defendem uma postura com a qual esta pesquisa coaduna, por entender-se que a educação, segundo os moldes tradicionais atuais, tende a dar lugar a novas práticas pedagógicas. $E$, enquanto não se procurar entender mais demoradamente os contextos sociais dos/as alunos/as, deixando que essa realidade interfira, efetivamente, nas práticas educativas, é difícil que novas concepções de ensino sejam aplicadas na escola, em busca de tornar as metodologias de ensino mais ativas e dinâmicas. Quem concorda com isso, também, é José Manuel Moran (2011), que afiança:

Os principais obstáculos para a aprendizagem inovadora são: o currículo engessado, conteudista; a formação deficiente de professores e alunos; a cultura da aula tradicional, que leva os professores a privilegiarem o ensino, a informação e o monopólio da fala. Também são obstáculos: o excessivo número de alunos, de turmas e de matérias que muitos professores assumem e a obsessão pela preparação para o vestibular das melhores universidades, o que concentra a 
atenção no conteúdo provável desse exame e não na formação integral do adolescente. (MORAN, 2011, p. 45).

Esses obstáculos foram sentidos no Curso Corpo, saúde, sexualidades, pois as/os participantes não corresponderam às expectativas e aos objetivos propostos para o curso, ao que, suponho, se deve ao fato de elas/eles estarem acostumadas/os com o modelo tradicional da educação. Ou seja, a ideia geral era contribuir para a formação docente não apenas no que concerne às temáticas relações de gênero e sexualidades, mas, também, para que os/as participantes pudessem experimentar formas alternativas e dinâmicas de ensino-aprendizagem, utilizando as tecnologias e uma metodologia ativa na educação. Contudo, sobrepujado pela cultura vigente, o curso não foi percebido como uma forma de mudança de paradigma educacional.

\section{Metodologia}

A costura metodológica desta pesquisa utiliza o pós-estruturalismo como linha de alinhavo, buscando problematizar o uso de diferentes artefatos multimídias, sob a ótica dos multiletramentos e das relações de intermultimidialidade, que podem ser estabelecidas entre textos, imagens, vídeos, entre outros, criando possibilidades de reflexão sobre as temáticas de relações de gêneros e sexualidades.

Este trabalho, por se propor a uma mudança na estrutura da forma de se pesquisar, adotou a metodologia pós-estruturalista ou pós-crítica, a qual se caracteriza, primordialmente, porque o seu desenho metodológico "não está (e nem poderia estar) fechado e decidido a priori e que não pode ser "replicado" do mesmo modo por qualquer pessoa, em qualquer tempo e lugar" (MEYER; PARAíSO, 2014 , p. 22). Dessa forma, a pesquisa com seres humanos, nesse caso com licenciandos/as, especialmente por meio de uma ferramenta tão dinâmica quanto uma rede social, envolve infinitas possibilidades de problematização, análise e produção do conhecimento, o que torna o processo ainda mais fascinante. E isso requer novos contornos metodológicos, como a que se utilizou nesta pesquisa.

Foi necessário, para tanto, uma metodologia que sustentasse a análise das produções advindas do curso e, ao mesmo tempo, dialogasse com o referencial pós-estruturalista com que teci esta pesquisa. Para tanto, escolhi fazer, nas palavras de Roque Moraes (2003) "uma tempestade de luz" (p. 192), por meio da análise textual discursiva, também denominada por esse autor como análise textual qualitativa, um processo de análise que se situa entre a abordagem textual e a discursiva. 
Considerei adequada essa abordagem, pois ela pauta-se em um processo de desconstrução que, a partir das novas interpretações reconstruídas por quem pesquisa, procura, assim como afirmam Dagmar Estermann Meyer e Marlucy Alves Paraíso (2014, p. 59): “abrir mão de enfoques teóricos que priorizam o caráter explicativo e prescritivo do conhecimento para assumir enfoques que estimulam a desnaturalização e a problematização das coisas que aprendemos a tomar como dadas".

Nesta pesquisa, nada estava dado, os sentidos foram sendo construídos a partir da ótica com que se observava o material advindo do curso, a fim de evidenciar como as relações de intermultimidialidade foram estabelecidas pelos/as participantes. Para tanto, utilizei os caminhos propostos pela análise textual discursiva que organiza a pesquisa em três momentos: a desconstrução textual; a análise das unidades escolhidas; e a problematização, que gera metatextos (textos que discorrem acerca de textos) sobre os recortes de análise (MORAES; GALIAZZI, 2016).

Significar e ressignificar foi o que pretendi fazer com o material empírico advindo desta pesquisa, inclusive, em sua apresentação final. E aqui faço uma ressalva a essa palavra. Final não no sentido de completude, término, trabalho encerrado, mas de ciclo que tem uma finalidade: propiciar o começo de muitos outros caminhos, tecidos, fios, rizomas, redes...

\section{Análise de dados: Música Meninos e Meninas e Crônica Pertencer}

Para exemplificar como a intermultimidialidade foi realizada, escolhi uma das atividades advindas do curso, a qual analisei em três etapas. O primeiro momento consistiu na seleção de um trecho do que foi escrito e postado pelo/a participante. No segundo momento, foram analisadas as intermultimidialidades em comparação com pressupostos de intertextualidade (KOCH; BENTES; CAVALCANTE, 2008). E, finalmente, a problematização foi feita em relação ao uso dos multiletramentos (ROJO, 2012), à demonstração de postura do/a participante (BARTON; LEE, 2015) e às implicações desse posicionamento quanto à articulação com teorias que abordam as temáticas relações de gêneros e sexualidades (CASTRO, 2012; RIBEIRO, 2010).

$\mathrm{Na}$ atividade selecionada, foi proposto que as/os participantes ouvissem a música Meninos $e$ Meninas, composta por Renato Russo, Dado Villa-lobos, Marcelo Bonfá e interpretada pela banda Legião Urbana, e refletissem sobre como a letra aborda os papéis sociais de meninos/homens e meninas/mulheres. Com base nisso, aconteceu uma discussão, por meio da ferramenta de bate-papo 
do Facebook, em que as/os participantes deveriam trazer outras referências, que dialogassem com a música. Destaco, desta atividade, o comentário de Amarelo ${ }^{13}$ :

Bom, acho que eu nunca tinha parado para realmente ouvir a música... E foi bem pesada... Quando eu ouvia em casa eu era criança e ficava lá brincando com minhas bonecas escondido das pessoas, não era a pessoa que "estou" hoje, eu prefiro usar o verbo estar ao verbo ser pois estamos sempre em constantes mutações... O trecho que mais me tocou foi este:

"Vai ver que é assim mesmo e vai ser assim pra sempre

Vai ficando complicado e ao mesmo tempo diferente

Estou cansado de bater e ninguém abrir

Você me deixou sentindo tanto frio

Não sei mais o que dizer"

Acho que este trecho define minhas maiores angústias, que é a de não me encaixar entre os padrões de gêneros que temos, e este trecho me leva pra uma trama de dúvidas sobre a minha esfera pessoal com a esfera social, das coisas que tenho que fazer para ser "aceito" ou pelo menos respeitado nessa sociedade que oprime e machuca, percebo que fico preso nisso quando é mais fácil para eu responder: "o que os outros esperam de mim?" sem nem ao menos saber o que eu espero de mim... Falando em angústia tem um texto da maravilhosa Clarice Lispector chamado "Pertencer" que ela fala sobre a angústia de não pertencer a nada, de se sentir avulso, de graça.

Posso postar aqui também, se quiserem $\because$ (Amarelo)

Em seguida, Amarelo postou a crônica, de Clarice Lispector, Pertencer, publicada originalmente no Jornal do Brasil, no dia 15 de junho de 1968, e uma imagem ${ }^{14}$ de um homem com os olhos e a boca cobertos por braços carregando as palavras: Celebrity (Celebridade), Consume (Consumo), Sensationalism (Sensacionalismo), Scandal (Escândalo), Sex tapes (Fitas de sexo) ${ }^{15}$ :

Um amigo meu, médico, assegurou-me que desde o berço a criança sente o ambiente, a criança quer: nela o ser humano, no berço mesmo, já começou.

Tenho certeza de que no berço a minha primeira vontade foi a de pertencer. Por motivos que aqui não importam, eu de algum modo devia estar sentindo que não pertencia a nada e a ninguém. Nasci de graça.

Se no berço experimentei esta fome humana, ela continua a me acompanhar pela vida afora, como se fosse um destino. [...]

A vida me fez de vez em quando pertencer, como se fosse para me dar a medida do que eu perco não pertencendo. E então eu soube: pertencer é viver. Experimenteio com a sede de quem está no deserto e bebe sôfrego os últimos goles de água de um cantil. E depois a sede volta e é no deserto mesmo que caminho. (LISPECTOR, 1999, p. 110).

13 A fim de preservar a identidade da/o participante, ela/ele foi denominada/o com uma cor, em vez de ser marcada/o por número, o que, considero, transmite um sentido de objetificação da pessoa e vai de encontro aos princípios desta pesquisa.
$14 \quad$ Imagem
disponível
em:
http://periodismeiconsciencia.org/wp-content/uploads/

2014/03/censura-3.jpg. Acesso em: 11 mar. 2017.

15 Tradução minha. 


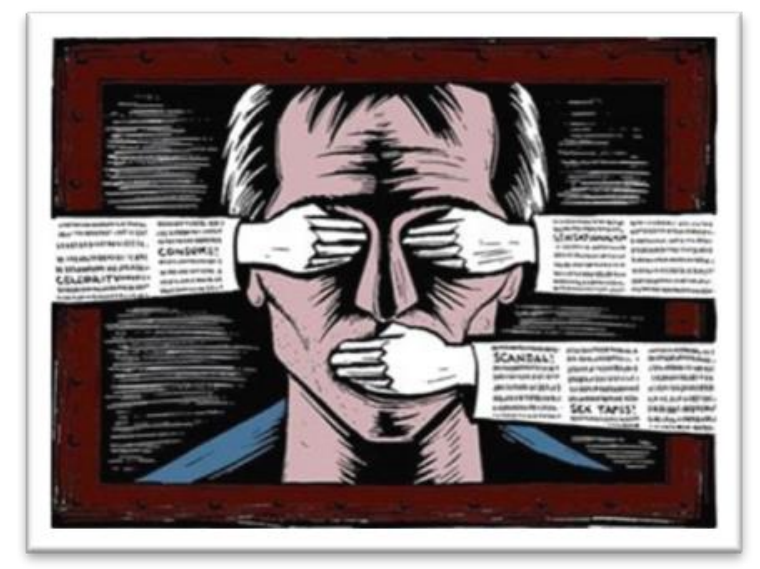

Figura 1 - Imagem utilizada para a intermultimidialidade

Amarelo disse que se lembrou da crônica, porque "ela fala sobre a angústia de não pertencer a nada, de se sentir avulso, de graça", em uma clara referência ao que diz o eu lírico do texto: "Por motivos que aqui não importam, eu de algum modo devia estar sentindo que não pertencia a nada e a ninguém. Nasci de graça" (LISPECTOR, 1999, p. 110). Por sua vez, a imagem representando um homem com os olhos e a boca também remetem à angústia, sentido que, para ser depreendido, requer que seja acessada a habilidade de leitura de textos verbais e não verbais, como preceituam as concepções de Roxane Rojo (2012) sobre os multiletramentos. Nesse ínterim, propor uma imagem que possibilitou a ampliação das discussões demonstrou, ainda, uma marcação de postura, conforme indicam David Barton e Carmen Lee (2015).

A partir desses recortes, foi possível perceber que Amarelo estabeleceu uma relação de intermultimidialidade entre a letra da música, a crônica e a imagem. Nesse caso, quando citou a música e remeteu à crônica, Amarelo estabeleceu intertextualidades temática e explícita. Já a aproximação entre os textos e a imagem se assemelhou ao que acontece na intertextualidade temática. Nesse caso, Amarelo fez uma clara demonstração de posicionamento, sobretudo porque explicou o motivo de suas escolhas e das relações que estabeleceu entre os artefatos multimídias.

Ao construir essa relação de intermultimidialidade, Amarelo conseguiu atingir o objetivo proposto para o curso, o qual dialoga com o que indica Cláudia Ribeiro (2010, p. 10): “os processos do ensinar e do aprender; do aprender e do ensinar nas temáticas de gênero e sexualidade são desafiadores, pois [...] são complexos, paradoxais, enigmáticos, polêmicos, muitas vezes proibidos, contraditórios, prazerosos".

Justamente por permitirem tantos diálogos, os processos de ensino-aprendizagem são tão complexos, mas, ao mesmo tempo, tão enriquecedores e especiais. E as muitas discussões que podem ser suscitadas referem-se a diversos aspectos. No caso dessa postagem, poderia ser discutida, por exemplo, a sensação de não pertencimento demonstrada por Amarelo, a qual advém, 
provavelmente, do fato de que, como afirma Roney Polato de Castro (2012, p. 148), "em nossa sociedade, o "masculino" e o "heterossexual" têm sido considerados padrões, ou seja, eles têm caráter de norma" e quem se distancia desse padrão acaba relegado à margem: "mulheres, homossexuais, bissexuais, travesti, transexuais, entre outros" (CASTRO, 2012, p. 148).

A afirmação do autor indica que as temáticas relações de gêneros e sexualidades precisam ser discutidas, conforme o que foi proposto pelo Curso Corpo, saúde, sexualidades, a fim de suscitar debates como: o estabelecimento de padrões não deveria, então, ser questionado, para que as pessoas marginalizadas não acabassem como na figura: silenciadas?

\section{Considerações Finais}

Com a realização de um curso de extensão utilizando uma rede social como o Facebook, quis demonstrar como as Tecnologias Digitais de Informação e Comunicação (TDIC) podem ser utilizadas na educação. Sobremaneira, para se aplicar o ensino híbrido, que busca rever os papéis de alunos/as e professores/as, para que haja mais interação e protagonismo estudantil na organização das aulas.

Esse processo inclui as diferentes oportunidades de trocas de ideias, leituras, discussões e ressignificações de conceitos e teorias. A começar pela escolha em usar relações de gêneros e, pluralizando ambos os termos, demonstrar que os gêneros estão relacionados a ações e atitudes próprias de cada pessoa. Outro posicionamento que assumi, a partir de diferentes pressupostos teóricos e sob a ótica dos multiletramentos, foi recontextualizar a terminologia artefatos multimídias e cunhar, para as relações entre eles estabelecidas, o termo intermultimidialidade.

Contribuir para a formação docente sobre as temáticas relações de gêneros e sexualidades foi a proposta do curso de extensão, tendo em vista que esses temas ainda não são discutidos com a profundidade necessária, tanto no ensino superior quanto na educação básica. Dessa forma, professoras/es acabam chegando despreparadas/os em sala de aula e não sabem lidar com situações cotidianas que, ao não serem problematizadas na escola, muitas vezes se transformam em casos de discriminação, opressão e violência.

Afinal, se uma educação de qualidade é aquela que procura contribuir para que as pessoas evoluam, isso inclui as discussões sobre como a sociedade se organiza e como os seres humanos interagem. Para tanto, é preciso respeito e diálogo. E isso inclui falar sobre como as relações de gêneros e as sexualidades refletem as personalidades humanas em todas as suas nuances de cores, formas, sons, sabores, percepções...

O diálogo entre pessoas pode começar pelo diálogo entre artefatos multimídias, cujas leituras, discussões, problematizações e criação de intermultimidialidades se transformam em metodologia que permite discussões críticas e amplas sobre relações de gêneros e sexualidades. $E$ 
não apenas sobre esses assuntos, mas abarcando qualquer outro tema. Além disso, essa prática pedagógica pode ser utilizada com qualquer faixa etária, de acordo com os objetivos de ensinoaprendizagem que o/a professor/a tenha.

Rizomas, redes, tecidos... De muitos fios foi composto este trabalho, integrando linguagens, tecnologias e sexualidades, sendo esse apenas o início das muitas pontas que ainda podem ser puxadas a partir das ideias aqui discutidas.

\title{
The use of the Facebook to work with gender and sexuality relations: potentialities for the
}

\section{extension of multiliteracies in teaching training}

\begin{abstract}
Among of so many particular (con)texts in the digital age, Facebook can be conceived as a tool for the realization of various educational practices. This article aims to analyze this point of view, from data collected in a course conducted in Facebook. The Teacher Training, initial or continuing, is still not approaching satisfactorily the discussions involving gender and sexuality (SILVA, 2015). Even more when this issue is made by the poststructuralist view (LOURO, 2012), associated to the development of multiliteracy abilities (ROJO, 2015). In this context Facebook can then be considered as a tool for enhancing knowledge, constituting a didactic material that combines the improvement of conceptual skills and methodological analysis to the expansion of knowledge related to multiliteracies.

Key words: Teacher Training. Gender relations and Sexualities. Multimedia artifacts. Intermultimidiality. Digital technologies.
\end{abstract}

\section{Referências}

ALMEIDA, Patricia Vasconcelos. Internet como fonte de material didático e como meio de ensino de língua estrangeira: uma investigação baseada na Teoria da Atividade. 2006. 242p. Tese (Doutorado) Universidade Estadual de Campinas, Instituto de Estudos da Linguagem, Campinas, SP. Disponível em: http://libdigi.unicamp.br/document/?code=vtls000380369. Acesso em: 15 abr. 2017.

BARTON, David; LEE, Carmen. Linguagem online: textos e práticas digitais. São Paulo: Parábola Editorial, 2015. 270 p.

BRAIT, Beth. Olhar e ler: verbo-visualidade em perspectiva dialógica. Bakhtiniana, São Paulo, v. 2, n. 8, p.43-66, jul./dez. 2013. Disponível em: $\underline{\text { http://www.scielo.br/ }}$ pdf/bak/v8n2/04.pdf. Acesso em: 7 abr. 2017.

BUTLER, Judith. Problemas de gênero: feminismo e subversão da identidade. Rio de Janeiro: Civilização Brasileira, 2003. 236 p.

CASTRO, Roney Polato de. Perspectivas da formação docente no enfrentamento ao sexismo e à homofobia. In: RIBEIRO, Cláudia Maria (Org.). Tecendo gênero e diversidade sexual nos currículos da educação infantil. Lavras: UFLA, 2012. p. 142-159. 
CORREIA, Pedro Miguel Alves Ribeiro; MOREIRA, Maria Faia Rafael. Novas formas de comunicação: história do Facebook - Uma história necessariamente breve. Alceu: Revista do Departamento de Comunicação Social da PUC-Rio, Rio de Janeiro, v. 14, n. 28, p.168-187, jan./jun. 2014. Disponível em: http://revistaalceu.com.puc-rio.br/media/alceu\%2028\%20-\%20168-187.pdf. Acesso em: 20 mar. 2017.

COUTO JUNIOR, Dilton Ribeiro do. Cibercultura, juventude e alteridade: aprendendo-ensinando com o outro no Facebook. Jundiaí: Paco Editorial, 2013. 164 p.

DELEUZE, Gilles; GUATTARI, Félix. Mil platôs: capitalismo e esquizofrenia. Vol. I. São Paulo: Editora 34, 1995. $128 \mathrm{p}$.

DIAS, Jaciluz; ALMEIDA, Patricia Vasconcelos. Tessituras: relações intertextuais em redações de avaliação seriada. In: SIELP - SIMPÓSIO INTERNACIONAL DE ENSINO DE LÍNGUA PORTUGUESA, 6., 2016, Uberlândia. Anais... Uberlândia: Edufu, 2017. p. 1853 - 1866. Disponível em: http://www.ileel.ufu.br/anaisdosielp/arquivos/anais sielp 2016.pdf. Acesso em: 22 abr. 2017. ISSN: 2237-8758.

FOUCAULT, Michel. História da sexualidade 1: a vontade de saber. São Paulo: Paz e Terra, 2014. 176 p.

$\mathrm{KOCH}$, Ingedore Grunfeld Villaça; BENTES, Anna Christina; CAVALCANTE, Mônica Magalhães. Intertextualidade: diálogos possíveis. 2. ed. São Paulo: Cortez, 2008. 166 p.

LÉVY, Pierre. Cibercultura. São Paulo. Ed. 34, 1999. 272 p.

LISPECTOR, Clarice. A Descoberta do Mundo. Rio de Janeiro: Rocco, 1999. 480 p.

LOURO, Guacira Lopes. Gênero, sexualidade e educação: uma perspectiva pós-estruturalista. 14. ed. Petrópolis, RJ: Vozes, 2012. 184 p.

MARCUSCHI, Luiz Antônio. Gêneros textuais no ensino de língua. In: Produção textual, análise de gêneros e compreensão. São Paulo: Parábola, 2008. p. 146-225.

MEYER, Dagmar Estermann; PARAÍSO, Marlucy Alves. Metodologias de pesquisa pós-críticas em educação. 2. ed. Belo Horizonte: Mazza Edições, 2014. 310 p.

MORAES, Roque. Uma tempestade de luz: a compreensão possibilitada pela análise textual discursiva. Ciência \& Educação: Bauru, SP, v. 9, n. 2, p. 191-210, 2003. Disponível em: http://dx.doi.org/10.1590/S151673132003000200004. Acesso em: 3 jun. 2017.

MORAES, Roque; GALIAZZI, Maria do Carmo. Análise textual discursiva. 3. ed. ljuí: Unijuí, 2016. 264 p.

MORAN, José Manuel. A educação que desejamos: novos desafios e como chegar lá. 5. ed. Campinas: Papirus, 2011. $174 \mathrm{p}$.

RIBEIRO, Cláudia Maria. Gênero e sexualidade na formação de educadoras e educadores: navegando pelas artes. In: ANPED SUL - ENCONTRO DE PESQUISA EM EDUCAÇÃO DA REGIÃO SUL, 8., 2010, Londrina. Anais... Londrina: UEL, 2010. p. 1 - $12 . \quad$ Disponível em: http://www.fastore.pt/museu/site/docs/Texto4.pdf. Acesso em: 13 mai. 2017.

ROJO, Roxane; BARBOSA, Jacqueline. Hipermodernidade, multiletramentos e gêneros discursivos. São Paulo: Parábola Editorial, 2015. 150 p.

Diversidade cultural e de linguagens na escola. In: ROJO, Roxane; MOURA, Eduardo. Multiletramentos na escola. São Paulo: Parábola, 2012. p. 11-31.

SCOTT, Joan Wallach. Gênero: uma categoria útil de análise histórica. Educação \& Realidade. Porto Alegre, v. 20, n. 2, jul./dez. 1995, p. 71-99. Disponível em: 
https://edisciplinas.usp.br/pluginfile.php/185058/mod resource/content/2/G\%C3\%AAneroJoan\%20Scott.pdf. Acesso em: 7 abr. 2017.

SILVA, Kelly da. Currículo e gênero: a sexualidade na formação docente. Curitiba: Appris, 2015. 250 p.

SILVA, Rodrigo Abrantes da; CAMARGO, Ailton Luiz. A cultura escolar na era digital: o impacto da aceleração tecnológica na relação professor-aluno, no currículo e na organização escolar. In: $\mathrm{BAClCH}$, Lilian; TANZI NETO, Adolfo; TREVISANI, Fernando de Mello. Ensino híbrido: personalização e tecnologia na educação. São Paulo: Penso, 2015. p. 169-190.

STELLMANN, Renata. A masculinidade na clínica. 2007. Dissertação (Mestrado) - Curso de Mestrado em Psicologia, Departamento de Psicologia, Pontifícia Universidade Católica do Rio de Janeiro, Rio de Janeiro, 2007. $248 \quad$ p. $\quad$ Disponível em: rio.br/pergamum/biblioteca/php/mostrateses.php?open $=1 \&$ arqtese $=051040207$ Indice.html. Acesso em: 1 maio 2017.

SUNAGA, Alexsandro; CARVALHO, Camila Sanches de. As tecnologias digitais no ensino híbrido. In: BACICH, Lilian; TANZI NETO, Adolfo; TREVISANI, Fernando de Mello. Ensino híbrido: personalização e tecnologia na educação. São Paulo: Penso, 2015. p. 141-154. 